\title{
Why do multiparous women with a history of vaginal delivery give birth by cesarean section?
}

\author{
Hale Göksever Çelik ${ }^{1}$, Ayşegül Bestel ${ }^{1}$, Engin Çelik ${ }^{2}$, Alev Atış Aydın ${ }^{1}$ \\ 'Department of Obstetrics and Gynecology, Kanuni Sultan Süleyman Training and Research Hospital, İstanbul, Turkey \\ ${ }^{2}$ Department of Obstetrics and Gynecology, Istanbul University Istanbul School of Medicine Hospital, Istanbul, Turkey
}

\begin{abstract}
Objective: A cesarean section (C-section) is performed to deliver a baby through the mother's abdomen. In recent years, the rate of incidences requiring a $\mathrm{C}$-section is steadily increasing all over the world. Advanced maternal age, chronic health problems, multiple pregnancies as a result of the development of assisted reproductive technologies, and an insufficient supplementary health network can be considered as the reasons why mothers and obstetricians prefer a C-section. Our study aimed to identify the risk factors for the need of C-section in women with a history of vaginal delivery.

Material and Methods: 238 multiparous women with a history of vaginal birth at 37-42 gestational weeks were enrolled in our study. 110 women had underwent C-section. Control group was chosen randomly from women giving birth by vaginal route.

Results: Overall, 238 multiparous women with a history of vaginal delivery at 37-42 gestational weeks were enrolled in our study. The history of operative delivery, that of labor induction and presence of meconium and the indication of admission to the delivery room were different between groups. A lower Bishop score and biophysical profile, smaller gestational period, and lower birth weight were associated with the group requiring a C-section, whereas older age and a long time interval from the previous birth were associated with the group not requiring a C-section.

Conclusion: A strategy involving either labor induction or not could be individualized for each patient to eliminate the risk factors for adverse outcomes. To identify criteria for the standardization of labor management, further studies are needed. (J Turk Ger Gynecol Assoc 2016; 17: 209-13) Keywords: Cesarean section, vaginal birth, multiparity
\end{abstract}

Received: 14 June, 2016 Accepted: 29 October, 2016

\section{Introduction}

A cesarean section (C-section) is performed to deliver a baby through the mother's abdomen. Unexpected conditions related to the baby such as the position of the baby, signs of fetal distress, and number of babies or related to the mother such as health problems and previous operations or abnormalities of placentation result in a requirement of C-section. Some mothers demand this delivery route because they think that it is relatively safe for the baby and herself.

In recent years, the rate of incidences of C-section is steadily increasing all over the world. This procedure was used for $37 \%$ of the deliveries in 2008 and more than $48.1 \%$ of the deliveries in 2013 in Turkey (1). Advanced maternal age, chronic health problems such as hypertension and diabetes mellitus, multiple pregnancies as a result of the development of assisted reproductive technologies, and an insufficient supplementary health network can be considered as the reasons why mothers and obstetricians prefer a C-section (2). Our study aimed to identify the risk factors for C-section in women with a history of vaginal delivery. The primary outcome for the study was a requirement of a C-section in these women.

\section{Material and Methods}

A hospital-based retrospective cohort study comprising 238 multiparous women was performed at the Department of Obstetrics and Gynecology at Kanuni Sultan Süleyman Training and Research Hospital. Women with a history of vaginal delivery were included. In total, 110 women had undergone a C-section. An age-matched control group was randomly chosen from women giving birth through the vaginal route. Operative deliveries with vacuum or forceps and patients with fetal demise and a prior C-section were excluded from the study. All the demographic and clinical characteristics of the patients were recorded from our own hospital's database, including age, number of gravida and parity, body mass index (BMI), weight gain, time interval from previous delivery, birth weight of previous and present babies, and gestational week. We analyzed the presence of maternal health problems (diabetes mellitus, goiter, hypertension, asthma, epilepsy, psychotic diseases, and cardiac problems), indication for admission to the delivery room and that of C-section, placental location, presence of meconium, history of operative intervention, and induction in previous birth(s). Records were also reviewed to identify induction and route of delivery. 
All the gestational weeks were confirmed by a first trimester ultrasound. BMI was presented as a measure of body fat based on height and weight. BMI was categorized based on the World Health Organization (WHO) classification into underweight (less than 18.5), normal weight (18.5-24.9), overweight (25-29.9), obese (more than 30 ), and morbidly obese (more than 40).

In our hospital, the biophysical profile (BPP) and Bishop score were used to determine the stage of labor. The Bishop score is a quantitative means of describing the cervical status to decide the necessity of cervical ripening agents. The parameters in this score are cervical dilatation and effacement, the position and consistency of the cervix, and the station of the fetal head. If the Bishop score is $\leq 6$, we accept the cervix as unfavorable for vaginal delivery and apply agents such as prostaglandin E2 ovules (Propess ovule; Ferring Medical, İstanbul, Turkey) for cervical ripening. Labor induction, when indicated, is performed using oxytocin infusion (Synpitan forte; Deva Medical, İstanbul, Turkey) with or without amniotomy. It was performed in women with no effective contractions accompanying cervical dilatation and effacement to promote delivery.

Labor pain, rupture of membranes, post-term pregnancy, suspicious non-stress test (NST), extreme vaginal bleeding, preeclampsia/chronic hypertension, growth restriction, or oligohydramnios were included as indications for admission to the delivery room. The reasons to proceed with a C-section included fetal distress, malpresentation, macrosomia, multiple pregnancies, failure to progress in labor or failed induction, fetal anomalies, and maternal clinical conditions.

Our study was designed as a retrospective cohort study and conducted according to the Helsinki Declaration. There was no ethical approval needed because we collected data of the patients from the records in the archives and we did not document any personal information. Also, in our hospital, informed consent was obtained from every patient for the use of medical information in scientific publications.

\section{Statistical analysis}

Statistical analysis was performed with the Statistical Package for the Social Sciences (SPSS Inc.; Chicago, IL, USA) statistics 22.0 version for Windows. Differences in the mean values and characteristics between the groups were analyzed with the independent samples t-test and chi-square test. The means are presented herein with the standard deviation. $\mathrm{p}<.05$ was considered statistically significant. The correlation coefficients and their significance were calculated using the Pearson test. For the multivariate analysis, the possible factors identified with univariate analyses were further entered into the logistic regression analysis to determine the independent predictors of patient outcome.

\section{Results}

Two hundred thirty-eight multiparous women with a history of vaginal birth at 37-42 gestational weeks were enrolled in our study. Of these, $46.2 \%$ of patients had given birth through a C-section. The mean age of all the women was $29.8 \pm 5.5$
Table 1. Demographic and clinical characteristics of patients

\begin{tabular}{|c|c|}
\hline Characteristics & $\begin{array}{c}\text { Number }(\%) \text { or } \\
\text { mean } \pm \text { standard } \\
\text { deviation }\end{array}$ \\
\hline Maternal age & $29.8 \pm 5.5$ \\
\hline BMI $\left(\mathrm{kg} / \mathrm{m}^{2}\right)$ & $30.4 \pm 4.6$ \\
\hline Gravida & $3.3 \pm 1.5$ \\
\hline Parity & $2.0 \pm 1.4$ \\
\hline \multicolumn{2}{|l|}{ Maternal health problems } \\
\hline Absent & $204(85.7)$ \\
\hline Present & $34(14.3)$ \\
\hline Weight gain (kg) & $10.5 \pm 4.4$ \\
\hline Time interval from previous birth (years) & $5.4 \pm 3.7$ \\
\hline Gestational week (weeks) & $38.0 \pm 3.0$ \\
\hline \multicolumn{2}{|l|}{ Placental location } \\
\hline Anterior & $139(58.4)$ \\
\hline Posterior & $70(29.4)$ \\
\hline Left lateral & $7(2.9)$ \\
\hline Right lateral & $13(5.5)$ \\
\hline Fundal & $9(3.8)$ \\
\hline Bishop score & $7.7 \pm 3.5$ \\
\hline BPP & $3.5 \pm 1.0$ \\
\hline \multicolumn{2}{|l|}{ Induction } \\
\hline Absent & $96(40.3)$ \\
\hline Present & $142(59.7)$ \\
\hline Birth weight (g) & $3116.3 \pm 763.7$ \\
\hline \multicolumn{2}{|l|}{ Meconium } \\
\hline Absent & $226(95)$ \\
\hline Present & $12(5)$ \\
\hline \multicolumn{2}{|l|}{ Induction of previous birth } \\
\hline Absent & $108(45.4)$ \\
\hline Present & $130(54.6)$ \\
\hline \multicolumn{2}{|l|}{ Operative intervention of previous birth } \\
\hline Absent & $234(98.3)$ \\
\hline Present & $4(1.7)$ \\
\hline Birth weight of previous child (g) & $3165.9 \pm 571.3$ \\
\hline
\end{tabular}

years. The mean BMI of all the women was 30.4 4 4.6. Of all the women, 96 (40.3\%) had spontaneous labor, whereas 142 (59.7\%) women received labor induction. All the demographic and clinical characteristics of the patients are represented in Table 1. The most frequent indication for admission to the delivery room was labor pain, whereas that for C-section was fetal distress (Table 2).

Table 3 shows the mean levels in terms of the characteristics of the women according to the route of delivery. There was a statistically significant difference between groups based on a history of operative delivery, that of labor induction and pres- 
Table 2. Indications on admission and for C-section

\begin{tabular}{|c|c|c|c|}
\hline \multicolumn{2}{|c|}{ Indication on admission } & \multicolumn{2}{|c|}{ Indication for C-section } \\
\hline Labor pain & $167(70.2)$ & Fetal distress & $42(38.2)$ \\
\hline Rupture of membranes & $29(12.2)$ & Malpresentation & $16(14.5)$ \\
\hline Post-term pregnancy & $11(4.6)$ & Macrosomia & $12(10.9)$ \\
\hline Preeclampsia/chronic hypertension & $10(4.2)$ & Multiple pregnancies & $12(10.9)$ \\
\hline Oligohydramnios/IUGR & $9(3.8)$ & Obstructed labor & $10(9.1)$ \\
\hline Suspicious NST & $9(3.8)$ & Preeclampsia & $7(6.4)$ \\
\hline \multirow[t]{4}{*}{ Vaginal bleeding } & $3(1.3)$ & Placentation anomalies & $3(2.7)$ \\
\hline & & Fetal anomalies & $3(2.7)$ \\
\hline & & Maternal conditions & $3(2.7)$ \\
\hline & & Cord problems & $2(0.8)$ \\
\hline
\end{tabular}

Table 3. Comparison of characteristics between patients according to the route of delivery

\begin{tabular}{|l|c|c|c|}
\hline Characteristics & Vaginal delivery (Patient number: 128) & C-section (Patient number: 110) & p \\
\hline Maternal age & $29.4 \pm 5.6$ & $30.4 \pm 5.3$ & NS \\
\hline BMI $\left(\mathrm{kg} / \mathrm{m}^{2}\right)$ & $30.1 \pm 4.3$ & $30.8 \pm 5.0$ & NS \\
\hline Gravida & $3.2 \pm 1.3$ & $3.4 \pm 1.7$ & NS \\
\hline Parity & $1.8 \pm 1.2$ & $2.1 \pm 1.6$ & NS \\
\hline Weight gain $(\mathrm{kg})$ & $10.0 \pm 3.8$ & $11.0 \pm 5.0$ & NS \\
\hline Time interval from previous birth (years) & $4.7 \pm 3.8$ & $6.1 \pm 3.5$ & .003 \\
\hline Gestational week (weeks) & $38.9 \pm 2.0$ & $37.0 \pm 3.6$ & $<0.001$ \\
\hline Bishop score & $9.5 \pm 2.7$ & $5.6 \pm 3.0$ & $<0.001$ \\
\hline BPP & $3.8 \pm 0.6$ & $3.1 \pm 1.2$ & $<0.001$ \\
\hline Birth weight (kg) & $3270.2 \pm 516.7$ & $2937.3 \pm 947.1$ & .001 \\
\hline Birth weight of previous child $(\mathrm{kg})$ & $3168.1 \pm 555.5$ & $3163.5 \pm 591.7$ & $\mathrm{NS}$ \\
\hline $\begin{array}{l}\text { BMI: body mass index; BPP: biophysical profile; C-section: cesarean section; NS: not significant } \\
\text { Used independent samples t-test; } \mathrm{p}<0.05 \text { accepted as statistically significant. }\end{array}$ \\
\hline
\end{tabular}

ence of meconium, and the indication for admission to the delivery room (Table 4).

Bivariate correlation analysis demonstrated that a lower Bishop score and biophysical profile, smaller gestational period, and lower birth weight were associated with the group requiring a C-section, whereas older age and a long time interval from the previous birth were associated with the group not requiring a $\mathrm{C}$-section. Table 5 shows the results of the logistic regression analysis. The presence of meconium was identified as the strongest factor to proceed with C-section in our study population.

\section{Discussion}

We analyzed the predictors for C-section in multiparous women with a history of vaginal delivery. Approximately $40 \%$ of all the women gave birth spontaneously without labor induction, whereas $76.1 \%$ of the women requiring induction gave birth by the vaginal route. Many studies claimed that induction was a significant risk factor for C-section, especially in nulliparous women (3-7). Rattigan et al. (8) also reported that the rates of operative delivery increase in women who receive labor induction regardless of parity. According to these studies, nulliparity is an independent risk factor for C-section in women who receive labor induction. However, the difference between these studies and our study is the study population, which is entirely multiparous. On the other hand, induction did not increase the risk of surgical delivery in multiparous women according to our results. Lee et al. (9) proposed that the rate of C-section was associated with the Bishop score but not impacted by labor induction; this is consistent with to our results. As a result, there is no certainty that induction increases the risk for C-section. There are also some situations in which labor induction is required for maternal and infant health (10).

In our study, a longer time interval from the previous birth, smaller gestational week, lower Bishop score and BPP, and a lower birth weight were determined as predictors for C-section. Similar to our results, Ennen et al. (11) accepted that an advanced maternal age, high BMI, and low Bishop score 
Table 4. Comparison of characteristics between patients according to the route of delivery

\begin{tabular}{|c|c|c|c|}
\hline Characteristics & Vaginal delivery (Patient number: 128) & C-section (Patient number: 110) & $\mathbf{p}$ \\
\hline \multicolumn{4}{|l|}{ Maternal health problems } \\
\hline Absent & $112(54.9)$ & $92(45.1)$ & \multirow{2}{*}{ NS } \\
\hline Present & $16(47.1)$ & $18(52.9)$ & \\
\hline \multicolumn{4}{|l|}{ Placental location } \\
\hline Anterior & $80(57.6)$ & $70(45.8)$ & \multirow{5}{*}{ NS } \\
\hline Posterior & $33(47.1)$ & $38(53.5)$ & \\
\hline Left lateral & $8(61.5)$ & $5(38.5)$ & \\
\hline Right lateral & $2(28.6)$ & $5(71.4)$ & \\
\hline Fundal & $5(55.6)$ & $4(44.4)$ & \\
\hline \multicolumn{4}{|l|}{ Induction } \\
\hline Absent & $20(20.8)$ & $76(79.2)$ & \multirow{2}{*}{$<0.001$} \\
\hline Present & $108(76.1)$ & $34(23.9)$ & \\
\hline \multicolumn{4}{|l|}{ Meconium } \\
\hline Absent & $126(55.8)$ & $100(44.2)$ & \multirow{2}{*}{.014} \\
\hline Present & $2(16.7)$ & $10(83.3)$ & \\
\hline \multicolumn{4}{|l|}{ Induction of previous birth } \\
\hline Absent & $56(51.9)$ & $52(48.1)$ & \multirow{2}{*}{ NS } \\
\hline Present & $72(55.4)$ & $58(44.6)$ & \\
\hline \multicolumn{4}{|l|}{ Operative intervention of previous birth } \\
\hline Absent & $128(54.7)$ & $106(45.3)$ & \multirow{2}{*}{.044} \\
\hline Present & 0 & $4(100)$ & \\
\hline \multicolumn{4}{|l|}{ Indication on admission } \\
\hline Labor pain & $105(62.9)$ & $62(37.1)$ & \multirow{7}{*}{$<0.001$} \\
\hline Rupture of membranes & $10(34.5)$ & $19(65.5)$ & \\
\hline Post-term pregnancy & $7(63.6)$ & $4(36.4)$ & \\
\hline Preeclampsia/chronic hypertension & $2(20)$ & $8(80)$ & \\
\hline Oligohydramnios/IUGR & $3(33.3)$ & $6(66.7)$ & \\
\hline Suspicious NST & $1(11.1)$ & $8(88.9)$ & \\
\hline Vaginal bleeding & 0 & $3(100)$ & \\
\hline
\end{tabular}

increased the possibility of C-section. We matched the ages of women between the control group and the study group to eliminate the effect of age on our results. Pregnancies with a smaller gestational week usually consult with an unfavorable cervix, which indicates a lower Bishop score and BPP, resulting in surgical delivery (12). Because of this, the duration of labor prolongs until full cervical dilatation and effacement. As the number of gravida increases, the possibility of many adverse outcomes, such as malpresentation, increases, which could be an indication for a C-section. We found a difference between the vaginal birth group and $\mathrm{C}$-section group according to the number of gravida and parity.

Interpregnancy interval is also important for predicting C-section during labor. A longer time interval between pregnancies increased the risk for C-section. The most effective reason was thought to be advancing maternal age.

Many studies showed that there is an increased risk for surgical deliveries among women with chronic health problems in contrast to our results (13). Because the age of our study population was relatively younger, maternal health problems did not affect the risk for C-section.

We did not find any difference between the groups according to placental location, similar to many other studies. If the woman had a history of operative delivery with vacuum or forceps, the risk for surgical delivery increased.

The most important parameter that increased the rate of C-section was the presence of meconium in our results. If we encounter a pregnant woman with these factors, we should 
Table 5. Results of the logistic regression analysis

\begin{tabular}{|l|c|c|}
\hline Risk factors & RR (95\% CI) & p \\
\hline Maternal health problems & $1.21(0.94-1.56)$ & NS \\
\hline Gestational weeks & $0.80(0.70-0.90)$ & .002 \\
\hline Indication on admission & $1.04(0.86-1.25)$ & NS \\
\hline Bishop score & $0.67(0.60-0.75)$ & $<0.001$ \\
\hline Presence of meconium & $12.94(2.30-73.24)$ & .004 \\
\hline $\begin{array}{l}\text { RR: risk ratio; CI: confidence interval; NS: not significant } \\
\text { Used binary logistic regression analysis, p<0.05 accepted as statistically } \\
\text { significant. }\end{array}$ \\
\hline
\end{tabular}

ensure a careful planning during follow-up of their pregnancy. If we look at the indications on admission, there was significant difference between the vaginal birth group and the C-section group. Rupture of membranes, preeclampsia or chronic hypertension, oligohydramnios with or without growth restriction, fetal distress with suspicious NST, or any vaginal bleeding were associated with a higher rate of C-section, because these conditions require a shorter delivery time and emergency interventions if necessary, resulting in surgical deliveries (14).

Labor pain and post-date pregnancy as indications on admission did not make a difference to the route of delivery. Many studies show that there is not sufficient evidence available about whether induction should be applied or not in these conditions (15).

Derbent et al. (16) identified that decreased physical activity is statistically associated with an increased risk of C-section besides the other factors. We did not conclude that result. Besides this, we also did not compare the perinatal morbidity and mortality, because of limited data from our hospital's database and due to the retrospective study design. This can be accepted as a weakness of our study. But the important distinction of our study from the others is the investigation of the predictors for C-section in multiparous women with a history of vaginal birth. To identify criteria for the standardization of labor management, further studies are needed.

\section{Ethics Committee Approval: N/A.}

Informed Consent: Written informed consent was obtained from patients who participated in this study.

Peer-review: Externally peer-reviewed.

Author Contributions: Concept - H.G.Ç., E.Ç.; Design - H.G.Ç., E.Ç.; Supervision - A.A.A.; Resources - H.G.C., A.B.; Materials - H.G.C., A.B.; Data Collection and/or Processing - H.G.C.., A.B.; Analysis and/or Interpretation - H.G.Ç.; Literature Search - H.G.Ç.; Writing Manuscript H.G.Ç.; Critical Review - E.C.., A.A.A.

Conflict of Interest: No conflict of interest was declared by the authors.
Financial Disclosure: The authors declared that this study has received no financial support.

\section{References}

1. Hacettepe University Institute of Population Studies (2014), "2013 Turkey Demographic and Health Survey". Hacettepe University Institute of Population Studies, T.R. Ministry of Development and TÜBITAK, Ankara, Turkey.

2. Ferrari AP, Carvalhaes MA, Parada CM. Association between prenatal and parturition in the supplementary health network andelective cesarean section. Rev Bras Epidemiol 2016; 19: 75-88.

3. Yeast JD, Jones A, Poskin M. Induction of labor and the relationship to cesarean delivery: A review of 7001 consecutive inductions. Am J Obstet Gynecol 1999; 180: 628-33.

4. Seyb ST, Berka RJ, Socol ML, Dooley SL. Risk of cesarean delivery with elective induction of labor at term in nulliparous women. Obstet Gynecol 1999; 94: 600-7.

5. Johnson AM. Evaluating outcomes of labor inductions beyond 39 weeks of gestation. Obstet Gynecol 2014; 123: 58S.

6. Thorsell M, Lyrenas S, Andolf E, Kaijser M. Inducion of labor and the risk for emergency cesarean section in nulliparous and multiparous women. Acta Obstet Gynecol Scand 2011; 90: 1094-99.

7. Levine LD, Hirshberg A, Srinivas SK. Term induction of labor and risk of cesarean delivery by parity. J Matern Fetal Neonatal Med 2014; 27: 1232-6.

8. Rattigan MI, Atkinson AL, Baum JD. Delivery route following elective induction of labor at term: Analysis of 807 patients. J Clin Med Res 2013; 5: 305-8.

9. Lee HR, Kim MN, You JY, Choi SJ, Oh SY, Roh CR, et al. Risk of cesarean section after induced versus spontaneous labor at term gestation. Obstet Gynecol Sci 2015; 58: 346-52.

10. Caughey AB, Sundaram V, Kaimal AJ, Cheng YW, Gienger A, Little $\mathrm{SE}$, et al. Maternal and neonatal outcomes of elective induction of labor. Evid Rep Technol Assess (Full Rep) 2009; 176: 1-257.

11. Ennen CS, Bofill JA, Magann EF, Bass JD, Chauhan SP, Morrison JC. Risk factors for cesarean delivery in preterm, term and post-term patients undergoing induction of labor with an unfavorable cervix. Gynecol Obstet Invest 2009; 67: 113-7.

12. Vahratian A, Zhang J, Troendle JF, Sciscione AC, Hoffman MK. Labor progression and risk of cesarean delivery in electively induced nullipars. Obstet Gynecol 2005; 105: 698-704.

13. Teixeira C, Correia S, Barros H. Risk of caesarean section after induced labour: do hospitals make a difference? BMC Research Notes 2013; 6: 214.

14. Horowitz KM. Induction of labor for fetal growth restriction. Obstet Gynecol 2014; 123: 56S.

15. Wennerholm UB, Hagberg $\mathrm{H}$, Brorsson B, Bergh C. Induction of labor versus expectant management for post-date pregnancy: Is there sufficient evidence for a change in clinical practice? Acta Obstet Gynecol Scand 2009; 88: 6-17.

16. Derbent AU, Karabulut A, Yıldırım M, Simavlı SA, Turhan NÖ. Evaluation of risk factors in cesarean delivery among multiparous women with a history of vaginal delivery. J Turkish-German Gynecol Assoc 2012 ; 13: 15-20. 